\title{
Organizational Learning and the Internationalization Sigmoid
}

\author{
Frank F. Cotae
}

\begin{abstract}
The article aims at pointing out the complex relationship between a MNE's leadership, focus and importance of organizational learning in the context of a successful internationalization process. Leadership's direction and vision from a learning organization perspective is looked as methodical and synthetic theoretical modes are intersected. The results of such junction bring to the forefront the relationship between the degrees of voluntarism's subscribed to by a firm in the context of organizational learning and the latter's impact upon a firm's internationalization related processes. In graphic form it is advanced that a firm needs to progress from organizational learning to a learning organization and based on this transition should follow with internationalization decisions. Just as the title suggests the paper also presents the theoretical scaffold for internationalization and organizational learning.
\end{abstract}

Index Terms - Internationalization, organizational learning, learning organization, voluntarism.

\section{INTRODUCTION}

The paper is organized into several sections, each presenting a different facet of the internationalization and learning organization points. Each section contains documentation in support of prescribed title and is substantiated by a graphic representation. Representations that intersect, for the purpose of pursuing organizational learning in the process of building a learning organization; organization see as enabled to make apt decisions with regards to undertaking internationalization activities.

\section{INTERNATIONALIZATION}

Internationalization is defined as the "process by which firms increase their awareness of the influence of international activities on their future, and establish and conduct transactions with other firms from other countries" [1]. Most of the documented rationales for business entities (SME/MNE) choosing to internationalize their operations fall into three categories: reduce risk, increase profitability, and allow for learning from the core capabilities offered by global partners [2]. These in turn are expected to provide value for future business activities. Although most related literature seems to promote internationalization as the appropriate direction underlying a firm's superior performance attainment [3]-[7], there are voices that doubt any linear relationship between a firm's degree of globalization and its level of performance [7]-[9]. Other voices merely question the process, devoid of leadership interaction, as the absolute

Mamuscript received March 10, 2013; revised May 12, 2013.

F. Cotae is with International Business at Mount Royal University, Calgary, Canada (e-mail fcotae@mtroyal.ca). guarantee for increased performance [10]. In summary, internationalization and leadership are seen as the key components resulting in increased or positive firm performance [11]. A multi-stage and s-curve hypothesis is advanced here as the model for a multinational firm degree of expansion (DOI) and performance (P) relationship [12]. There are three distinct stages of internationalization in the life of a firm, best exemplified by the General Sigmoid [4], [12], [13] model set out in Fig. 1: Stage I (early internationalization); Stage II (later internationalization); and Stage III (excessive internationalization). At the first stage a multinational is expected to incur costs as it sets up "shop" in a foreign place [14], [15] yet these costs are expected to be recovered during the second stage as the firm's performance reaches superior results. The third stage has been a matter of debate as firms engaged in global operations eventually reach a point where increasing the degree of internationalization becomes counterproductive [1] and the firm gradually reaches a level of operational saturation. The saturation point is where the core operational capabilities of a firm are no longer adequate for servicing a large number of global customers, vendors, subsidiaries, retail channels, and associates.

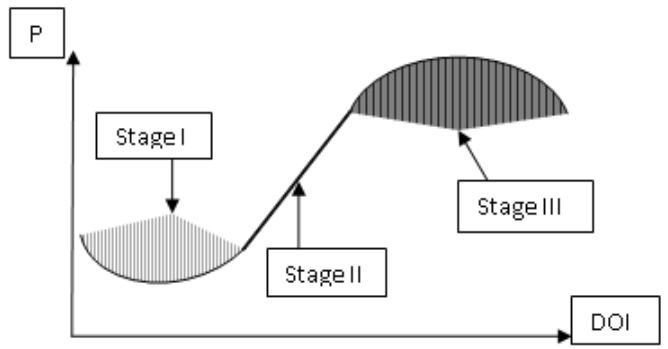

Fig. 1. The general sigmoid 3-stage model.

In addition, during the third stage the cost of maintaining a global operation and/or growing internationally renders the internationalization strategy inefficient and usually requires efforts outside a firm's realm of operational logistics/realities. As a result, productivity and profits are expected to decline. Current research has not yet produced a definitive model or factor by virtue of which this stage on internationalization can be predicted or its effects ameliorated, postponed, or diminished [16]. It is therefore necessary for an SME/MNE to continuously attempt to assess and forecast its costs before pursuing higher degrees of internationalization. The task of assessing forecasts, design growth strategies and operational related direction lies with the firm's operational apex and it should be the result of introspective process that should be based on information analysis; analysis seen as being determined by a firm's ability to learn and communicate information. 


\section{ORGANIZATIONAL LEARNING}

The concept of organizational learning, the piece we see connected to internationalization, is seen as instrumental to a business entity success and competitive advantage acquisition and this segment relies heavily on the work and research of [17] and an in-depth look would also be taken with regards to the types of organizational learning seen to affect firms. Four different perspectives of the idea of learning organization have been advanced, as well as a specific label for each of them, as a way of simplifying the communication for the underlying idea. First, the term learning organization is used synonymously with old organizational learning, the knowledge that the individuals have learned (often over a certain time period) as "agents for the organization is stored in the organizational memory [17], [18]". Second, the term learning organization can mean an organization where the learning takes place at work and not on courses-learning at work. Third, the label can be used to describe an organization that facilitates the learning of all its employees-a learning climate. Fourth, a popular perspective today is to consider the "learning organization as an organic structure with a high degree of flexibility, in order to satisfy the customers of the company [19], [20]". The aim of creating a flawless semantic framework for the idea of learning organization emerges through the prism of the above four labels. However, the existence of different perspectives of the learning organization in the literature probably not only gives a vague picture of the overall concept but it also creates opportunities for companies to choose a variant of the idea that fits their strategic interest [21], [22]. Simply put by definition a learning organization presumes the existence of certain operational flexibility and commitment to learning, without which the benefits of learning do not permeate a firm's processes and decisions making activities.

The task of arriving at a definition of learning as a cognitive process remains somewhat formless, as some researchers define learning as a "change in behavior in response to a stimulus [21]". Other scholars suggest that "learning requires some conscious acquisition of knowledge or insight on the part of organization members" [23], [24]. Yet this knowledge is not seen as unrelated to organizational goals, activity, action or decision making, as it seen to be relevant not only to individual learning, but also to that of organizations. Contemporary theorists have noted that "organization learning means the process of improving actions through better knowledge and understanding [25]." Therefore is seems that an agreement had been reached with regards to including both cognitive and behavioral elements into the definition of organizational learning [26] Considering the existing research a definition of organizational learning, through the prism of an MNE's business purpose can be advance as being the action of "acquiring knowledge necessary for improving the strategic decision making process needed for successfully dealing with change stimuli [27]". Several researchers [28] have pointed out that MNE success relies upon the firm's ability to create a "knowledge warehouse" where information would be collected from a diverse array of sources- i.e. best competitor practices, country particular norms/values/legal environment, industry particular risk factor, geo-political facts - and accessed as foundation for any changes in strategic direction and/or goals formulation. Internationalization or increased levels of it are just such a goal formulation as the direction is seen to add value to an organizational position, be that financial or market share related.

There is no debate that the two terms share a strategic intent and purpose, yet the two concepts are not congruent [28]. Organizational learning point to a particular action on the part of a corporations, while a learning organization can be best portrayed best as a "mind set", a commitment to a certain environment [18].

The current research suggests that gender, age, managerial behavior and actual training received are determinants of organizational learning. Organizational learning findings indicate [29] that there are "several structural factors that predict successful learning". Their initial observations about shared understandings and experiences revealed that "the concept of the learning organization is quite distinct from the process of learning undertaken by its individual members [18]". People embody learning in their own minds, but organizations have no "minds" except in a figurative sense. Organizations have to develop the institutional structures through which experience can be gathered and accumulated, and embodied in organizational routines, also called “organizational memory [20].

Organizational learning is seen to require two defining characteristics for its existence:

(a) Enable managers not only to act in a way that is perceived as fair, but to develop mechanisms which allow all groups of employees and managers to be able to articulate views. Employees need to be part of the learning process by generating "best practices" and continuous improvement, at the same time as maintaining a genuine level of autonomy. Open communication of views, ideas and opinions is seen as of intrinsic value [27].

(b) Guarantee not only that learning is a two-way process, but also that employees gain benefit from formal learning processes. Developing training courses that have applicability to employees' lives outside of the workplace and accepting that employees have skills that they can bring to the workplace, are important steps in developing organizational learning [27].

\section{TYPES OF ORGANIZATIONAL LEARNING}

The voluntarism-determinism refers to the extent to which people and their institutions are "deemed intelligent and independent role players rather than entities severely restricted in cognition and action [24]". Strategy oriented researchers, for example, adopt voluntaristic perspectives, allowing much latitude for free choice by decision makers [22]. Bureaucratic and pro-bureaucratic theorists are more deterministic and view "cognition as being channeled and behavior as being constrained [20]". Simply said the paradigms enable an organization to understand its own learning dimension based on its preferences and expectations. An organization aiming for an autocratic model based on strong preferences for bureaucracy and constraints would be less inclined to harvest benefits from a free choice, independent thinking staff. The reciprocal also stands with the caveat that many organizations could experience both forms depending of the situation or industry they operate in. 
Mills' synthesis points to "the voluntarism/determinism and methodical/emergent dimensions in combination evoke six common types of organizational learning: types that vary in their approaches, outcomes and contexts" [17], [18]. Three kinds of methodical learning and three kinds of emergent learning have been identified and are required to be examined in this assignment, each been distinguished by the level of voluntarism (by the constraints on thought and action).

For methodical learning the identified models are: analysis, experimentation and structural. Analysis, relates to the systematic approach that some managers undertake when formulating or implementing a particular strategy, they are said to scan the environment for information, to analyze that information along with data on internal resources and processes, for the purpose of generating action options (Beers at al., 1998; Caldwell, 2012). An alternative is chosen among these options. Ultimately, "management methodically evaluates achievements against predetermined objectives [19], [24]". Other researchers, while endorsing such methodical inquiry, have called attention to the time and resource limitations that constrain its thoroughness. Experimentation, points to the learning that is characterized by problem-driven search during which managers are said to engage in little reflection, as they are focused on gathering only the most accessible information leading to an "adequate" solution [30]. The third methodical mode that allows even less scope voluntarism is structural learning, which is driven by routines that standardize information processing and behavior. "Routines specify what data managers must gather and attend to, and they guide how managers interpret that information [18]".

Analysis, experiment and structural learning are all methodical and deliberate. They test ideas by systematically gathering factual information and changing behavior. Results are then monitored, and the cycle begins again. However, as we "move from analysis to routines there is a progression towards less voluntarism [17]". Analysis places few restrictions on learners, small experiments limit action, and routines channel both thought and action. Simply put there is an inverse degree of voluntarism as an organization moves from analysis towards the routine (structural) mode.

Three emergent forms of learning are also quite common, and again, they may be distinguished according to their degree of voluntarism. These identified forms are: synthesis, interactive and institutional. Researchers have pointed to "synthesis-learning that is intuitive and holistic [22]". Mills [17] finds that "such learning represents an instinctive form of pattern recognition-an ability to generate global insights about issues facing an organization [17]”. Its existence cannot be predicted as it may occur unintentionally as an internal trait present and applied uniquely to a particular manager.

A less voluntaristic form of emergent learning takes place via interaction and occurs when there is much social, cultural and political activity. Contrasting ideas and conflicting objectives among members of an organization may cause "search and choice to be based on-and limited by-a complex force field of different aims and issues [29], [18]". The chosen course of action derives from involved parties' interaction to other players, competitors, subsidiaries, associates, business partners.
Institutional learning, the third model for the emergent paradigm, is determined by ideologies and institutional forces such as laws, social norms or personal values that shape managerial thinking [22], [23]. Here learning is a product of indoctrination and possibly rigid social expectations, either subtle or direct [23], [24]. As one moves from synthetic to institutional learning there is a progression from more voluntaristic modes of emergent learning to more deterministic ones [17]. Synthesis places few restrictions on organizational players, political interaction limits action, and institutional learning channels both thought and action.

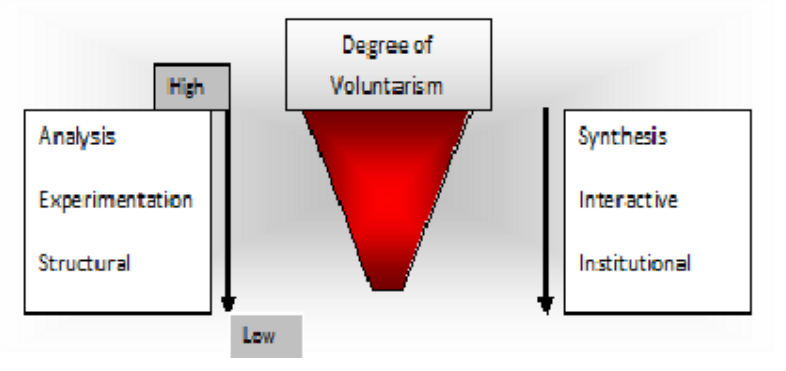

Fig. 2. Degree of voluntarism.

Fig. 2, a graphic representation for the degree of voluntarism expected during an organization's learning model movement indicates that during the analysis and synthesis stages the independent thinking and choice making appear at their highest point [25], [26]. Point which is not advance as being the optimum as each organization requires its own unique approach to learning.

\section{DEFINING A LEARNING ORGANIZATION}

The segment places a more finalizing touch upon what we see as defining a learning organization. Several different perspectives of the idea of learning organization have also been advanced, as well as a specific label for each of them, as a way of simplifying the communication for the underlying idea. First, the term learning organization is used synonymously with old organizational learning, the knowledge that the individuals have learned (often over a certain time period) as "agents for the organization is stored in the organizational memory [17], [18]". Second, the term learning organization can mean an organization where the learning takes place at work and not on courses-learning at work. Third, the label can be used to describe an organization that facilitates the learning of all its employees-a learning climate. Fourth, a popular perspective today is to consider the "learning organization as an organic structure with a high degree of flexibility, in order to satisfy the customers of the company [19], [24]". The aim of creating a flawless semantic framework for the idea of learning organization emerges through the prism of the above four labels. However, the existence of different perspectives of the learning organization in the literature probably not only gives a vague picture of the overall concept but it also creates opportunities for companies to choose a variant of the idea that fits their strategic interest [19], [21], [22].

Organizational learning and learning organizations are related yet not interchangeably terms, as a business enterprise can opt for a learning purpose without becoming a learning 
organization. The definitions advanced above are placed side by side- see Table I below- so as to clarify the terminology involved.

TABLE I: ORGANIZATIONAL LEARNING AND LEARNING ORGANIZATION

\begin{tabular}{|c|c|}
\hline $\begin{array}{l}\text { Organizational } \\
\text { Learning... }\end{array}$ & $\begin{array}{r}\text { Learning } \\
\text { Organizations... }\end{array}$ \\
\hline $\begin{array}{l}\text {...is the action of acquiring } \\
\text { knowledge necessary for } \\
\text { improving the strategic decision } \\
\text { making process } \\
\text {... is the beginning step for } \\
\text { becoming a learning } \\
\text { organization. } \\
\text {...occurs if a learning } \\
\text { organization is encouraged and } \\
\text { allowed to thrive by leadership. }\end{array}$ & $\begin{array}{l}\text {...is an organization that } \\
\text { adopts an organic structure } \\
\text { that includes and promotes a } \\
\text { work related learning climate } \\
\text { where knowledge is learned so } \\
\text { as to further/satisfy strategic } \\
\text { goals [27] }\end{array}$ \\
\hline
\end{tabular}

\section{INTERNATIONALIZATION AND LEARNING}

Intersecting a firm's goals, of higher degrees of internationalization, and its ability to transition to a learning organization — as concepts but also as practices - is becoming an imperative for an SME/MNE's sustained performance as it pursues global markets. Clearly, internationalization, learning, and firm performance are closely linked: based on firm accumulated knowledge through learning performance leaders decide if they need to reach new markets, if the context of having learned that they have the operational ability to do so and such decisions inherently lead to lower of higher degree of internationalization. An SME/MNE's knowledge base must play an integral role in making the appropriate decisions [18], [21] about the appropriate degree of internationalization and the operational resources needed for such strategic effort. The choice of what market to enter, timing of entry and the scalecommitment of resources - all are learning generated actions and can impact a company's ability to adapt to new demand of its operations, as well as support pre-expansion activities [29].

In looking at the sigmoid depiction above one sees that once a firm reaches the third stage, when results diminish or negative return are registered, a close dependency seems to emerge between decisions and results. Therefore, all signs seem to point to a learning organization as the active ingredient capable of preventing the diminishing results expected to occur during the third stage represented in the sigmoid, due to its access to privilege and accumulated information that was transmitted internally with regards to decision making [29], [30]. Closing the loop, we assert that learning derived decisions in a global mindset environment influence the degree and stage of internationalization [31], [24]. The question that needs asking is how learning prevents the firm from reaching a growth stage where growth ceases to produce value for the organization, in the context in which there are several types of organization influenced by a different degree of voluntarism. What type of an organization is best suited and open to allowing information to travel for the purpose of learning? A model set of activities would be for managers to conduct rigorous assessments with regard to the resources needed for pursuing additional globalization efforts [31]. Once the results are estimated, additional resources should be allocated if necessary and if available. If the additional costs are not feasible, the process can be stopped, even if this means reaching a mediating operational plateau results wise [18], [32].

The pursuit towards a learning organization is seen as a must, as an organization willing to learn is enabled to address market and competitive pressures with a higher degree of success [27]. The process of becoming a learning organization may be simplified with a better understanding of what kind of learning organization is intended and for what purpose. As the section concludes the need to formulate a clear definition for a learning organization arrives and it is advanced by this analyst as a compilation of the above four labels: a learning firm is an organization that adopts an organic structure that includes and promotes a work related learning climate where knowledge is learned, used and transferred so as to further and/or satisfy strategic goals [27]. If we replace strategic goals with achieving a higher degree of internationalization as a value creating purpose we see the connection and interdependence between the terms. The figure below shows the connection and interdependent sequence between the three concepts: organizational learning, learning organization and internationalization [31].

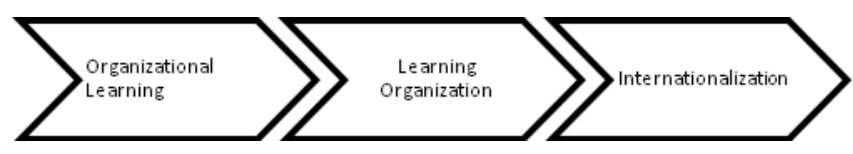

Fig. 3. General sequence.

Fig. 3 points clearly to the order of activities: first an organization needs to commit to learning and allowing knowledge to circulate, then as the process reaches a point at which the firm can be considered knowledgeable of its environment and the factors affecting it, therefore having become a learning organization, internationalization is undertaken. The additional point that needs to be made with regards to voluntarism in the context of organizational learning is that firms that encourage voluntarism and adopt an organizational type of learning that is conducive to information transfer, in this case and according to the theory advanced by [17] the two options with a best chance of success are: analysis and synthesis as they both seem to offer an answer to the following question: What type of an organization is best suited and open to allowing information to travel for the purpose of learning? An organization based on high degree of voluntarism, based on which adopts an analysis or synthesis mode of learning. The following graphic representation - Fig. 4 - summarizes these considerations.

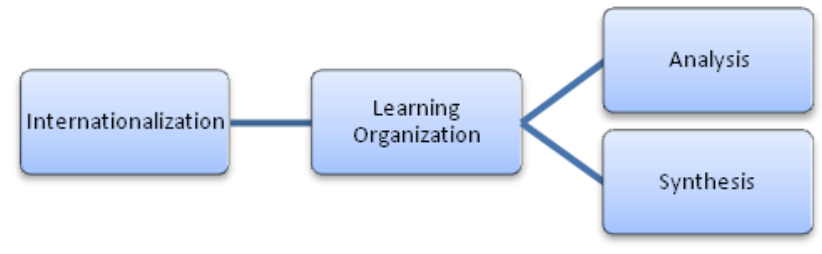

Fig. 4. Sequence based on learning mode.

\section{CONCLUSION, LIMITATIONS, AND FURTHER RESEARCH}

This paper aims not only at critically reviewing 
contemporary research on the internationalization process but also at pointing out the active role to be played by a firm' ability to become a learning organization and allow the information gathered through such a transition to substantiate global expansion decisions. Adopting the analysis choice from the methodical learning paradigm and the synthesis from its emergent learning counterpart are seen as the two forms of pursuits capable of delivering a learning organization that is enabled to make apt decisions with regards to internationalization levels. Adding to the model's applicability the concepts can be elongated into pointing that a flexible organization, aware and involved in collecting and disseminating information can react with certain expediency to changes in the internationalization environment and therefore make operational decisions that are well informed and sensible to future operational needs The limitation of the model is that it does not take into consideration the effect of unpredictable external factors affecting international performance - factors outside a leader's realm of knowledge, such as economic downturn in a geographic or economic area with global impact, political and social unrest, natural disasters, and possibly possible trade barriers and economic sanctions. The article also does not provide a timeline for knowledge accumulation and transfer and also does not point to the aftermath of a non-continuous or sequential learning commitment and process. Further research is expected to clearly articulate a set of guidelines for assessing organizational possibilities vis-à-vis the requirements of maintaining a continuously positive performance through internationalization.

\section{REFERENCES}

[1] P. W. Beamish, A. J. Morrison, A. C. Inkpen, and P. M. Rosenzwig, International Management, McGraw-Hill, 2003, Chapter 1, pp. 3-16.

[2] M. Glaum and M-J. Oesterle, " 40 years of research on internationalization and firm performance: More questions than answers?" Management International Review, vol. 47, no. 3, pp. 307-317, 2007.

[3] F. Contractor, "Is international business good for companies? The evolutionary or multi-stage theory on internationalization vs. the transaction cost perspective," Management International Review, vol. 47, no. 3, pp. 453-475, June 2007.

[4] A. Riahi-Belkaoui, "The effects of the Degree of Internationalization on Firm Performance," International Business Review, vol. 7, no. 3, pp. 315-321, 1998

[5] D. Sullivan, "Measuring the degree of internationalization of a firm," Journal of International Business Studies, vol. 25, no. 2, pp. 325-342, 1994.

[6] S. Tallman and J. Li, "Effects of international diversity and product diversity on the performance of multinational firms," Academy of Management Journal, vol. 39, no.1, pp. 179-196, 1996.

[7] J-F. Hennart, The Theories of Multinational Enterprises, Rugman, A./Brewer, The Oxford Handbook of International Business, Oxford University Press, pp. 127-149, 2001.

[8] J-F. Hennart, "The theoretical rationale for a multinationality and performance relationship," Management International Review, vol. 47, no. 3, pp. 423-443, 2007.

[9] J. Johanson and J. E. Vahlne, "The mechanism of internationalization," International Marketing Review, vol. 7, no. 4, pp. 11-24, 1990.

[10] E. Garcia-Canal and C. Lopez-Duarte, "Stock market reaction to FDI: Interaction between entry mode and FDI attributes," Management International Review, vol. 47, no. 3, pp. 393-422, 2007.

[11] G. A. Duarte and M. Rebelo, "Conditioning factors of an organizational learning culture,” Journal of Workplace Learning, vol. 2, no. 3, pp. 173-192, 2011.

[12] P. W. Beamish and J. Lu, "International diversification and firm performance: The s-curve hypothesis," Academy of Management Journal, vol. 47, no. 4, pp. 598-609, 2004.
[13] J. Johanson and J. E. Vahlne, "The internationalization process of the firm: A model of knowledge development and increasing foreign commitments," Journal of International Business Studies, vol. 8, no. 1, pp. 23-32, 2008.

[14] L. Eden and D. Thomas, "What is the shape of multinationality-performance relationship?" Multinational Business Review, vol. 12, no. 1, pp. 89-110, 2004.

[15] M. Javidan and J. L. Walker, "A whole new global mindset," People and Strategy, vol. 35, no. 2, pp. 37-41, 2012.

[16] M. Javidan, M Teagarden, and D. Bowen, "Making it overseas," Harvard Business Review, vol. 34, no. 4, pp. 127, 2010.

[17] D. Mills, "A preliminary typology of organizational learning: synthesizing the literature," Journal of Management, vol. 22, pp 485-490, 1996.

[18] W Zeying, D. Compeau, and N. Haggerty, "The effects of self-regulated learning processes on e-learning outcomes in organizational settings," Journal of Management Information Systems, vol. 29 , no. 1 , pp. 307-340, 2012.

[19] M. C. Beers, T. H. Davenport, and D. W. Long, "Successful knowledge management projects," Sloan Management Review, vol. 39, no. 2, pp. 43-57, 1998

[20] A. Amitabh and S. Sinha, "The learning continuum formal and informal learning experiences - enabling learning and creation of new knowledge in an organization," International Journal of Advanced Corporate Learning, vol. 5, no. 2, pp. 10-14, 2012.

[21] P. A. C. Smith, "The importance of organizational learning for organizational sustainability," The Learning Organization, vol. 19, no. 1, pp. 4-10, 2012.

[22] N. Marshall "Cognitive and practice-based theories of organizational knowledge and learning: incompatible or complementary?" Management Learning, vol. 40, no. 2, pp. 129-144, 2009.

[23] L. Field, "Exploring the political underbelly of organizational learning," The Learning Organization, vol. 18, no. 4, pp. 272-287, 2011.

[24] R. Caldwell, "Leadership and learning: a critical reexamination of senge's learning organization," Systemic Practice \& Action Research, vol. 25, no. 1, pp. 39-55, 2012.

[25] C. M. Fiol and M. Lyles, "Organizational learning," Academy of Management Review, IO: 803, pp. 8-13, 1985.

[26] Y. C. Huang and H. Shih, "A new mode of learning organization," International Journal of Manpower vol. 32, no. 5/6, pp. 623-644, 2011

[27] F. Cotae "Looking at the link between leadership and the internationalization sigmoid," Global Management Journal, vol. 3, no. 2, pp. 5-10, 2010.

[28] M. Chiarra, "Success factors in SME's internationalization process: An Italian investigation," Journal of Small Business Management; vol. 40, no. 2, pp. 144-153, 2002.

[29] S. Hollensen, Global Marketing, England, Pearson Education, Essex, 2007, Chapter 1, pp. 5-16.

[30] C. Kalantaridis, "Internationalization, strategic behavior, and the small firm: A comparative investigation," Journal of Small Business Management, vol. 42, no. 3, pp. 245-262, 2004.

[31] M. Amal and A. R. F. Filho, "Internationalization of small-and medium-sized enterprises: A multi case study," European Business Review, vol. 22, no. 6, pp. 608-623, 2010

[32] C. Hill and T. McKaig, Global Business Today, 3rd Canadian edition, McGraw-Hill Ryerson, 2012.

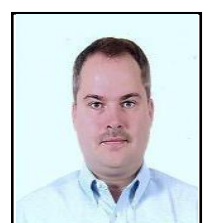

Frank F. Cotae has over 20 years of experience as manager, entrepreneur, consultant and professor. He is currently a professor of International Business at Bassett School of Business, Mount Royal University, Calgary, Canada. He has obtained a doctorate in international business management from ISM at St. John's University, New York City, US, an MBA from University or Arizona at Phoenix, Phoenix, US and a BA in finance from California State University, Fullerton, US. Dr. Cotae's research interests surround the internationalization, operations management, organizational learning, resource optimization and leadership studies. His research has been published in journals such as: Journal of American Academy of Business, International Journal of Business Studies and Current Topics in Management.

Dr. Cotae is a member of the Academy of International Business, Academy of Management and FITT Canada, a reviewer for International Business Review journal, International Journal of Entrepreneurship and is a Contributing Editor for the Journal for Global Commerce Research. 